\title{
MÁS SOBRE LA INSTITUCIONALIZACIÓN DE LA SOCIOLOGÍA JURÍDICA (Un agradecimiento y una respuesta a Realino Marra)
}

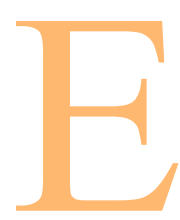

n el primer fascículo de los Materiali per una storia della cultura giuridica, correspondiente a 1991 (o sea el vol. XXI, n. 1, giugno), aparece una Nota firmada por Realino Marra, actualmente ricercatore di sociologia del diritto nella Facoltá di Giurisprudenza (Università degli Studi) di Genova, bajo el título de Lo statuto cientifico della sociología del diritto e la tutela weberiana.

$\mathrm{Su}$ contenido ha querido ser, básicamente, una recensión del volumen $\mathrm{n}^{\mathrm{o}} 5$ de la colección «Sociedad-Estado» que, bajo el título El derecho y sus realidades (Investigación y enseñanza de la sociología jurídica), por mi coordinado y editado en homenaje al Prof. em. Renato Treves, publicara PPU de Barcelona en 1989; el libro ofrecía las Ponencias y Comunicaciones que habían sido presentadas en las «Jornadas sobre la Investigación y la Enseñanza de la Sociología Jurídica», celebradas en el ámbito de la Universidad de Barcelona en el mes de Abril de 1988, con el doble objeto de rendir un homenaje al Prof. Treves y tratar de abrir una discusión acerca de la institucionalización académica de la sociología jurídica en España.

La diversa procedencia cultural de los ponentes y comunicantes a esas Jornadas, como la variedad de sus aportes que discurrieron tanto en el campo teórico cuanto en el empírico de la sociedad jurídica otorgaron al evento celebrado $\mathrm{y}$, por tanto, al libro publicado la capacidad de brindar un panorama sobre el «estado de la cuestión» que me parece quedó bien resumido en el subtítulo del volumen. Si bien la recensión de Marra es absolutamente válida, por lo cual me remito a las apreciaciones allí vertidas para que los lectores puedan contar con una precisa reseña sobre el libro, ella me convoca a escribir estas líneas por dos razones de diferente índole: una, emotiva y otra, científico-epistemológica. 
La primera se vincula con una antigua amistad, anudada con Marra en tierras saarlandesas y continuada en ámbitos italianos, afianzada por la admiración que me ha provocado su intenso trabajo de investigación sobre autores y campos -a los cuales aludiré más adelantefundamentales para el conocimiento socio-jurídico. La segunda de esas razones hace pie en las reflexiones que Marra ha vertido en la Nota publicada en los Materiali que van mucho más allá del comentario a los contenidos del volumen por mi coordinado y que constituyen -según mi opinión- unas ideas absolutamente originales, hasta el punto que llegan a poner en cuestión eso que él denomina con muchas propiedad la tutela weberiana de la sociología del derecho. Todo lo dicho, entonces, justifican un agradecimiento y una tentativa de respuesta a Marra.

I) La razón de índole emotiva a que aludo debe todavía ser ampliada, en lo que atañe a la admiración que he manifestado por el trabajo de Marra. En efecto, desde que Marra comenzó su labor de investigación ha demostrado poseer un verdadero Proyecto. Pero, ¿qué significa poseer un verdadero Proyecto cuando se habla de sociología jurídica y en lo que se refiere a la comprensión de las «funciones» que se han pretendido atribuir al derecho en las sociedades contemporáneas, habida cuenta que todo enfoque meta-normativo (como corresponde a la perspectiva disciplinaria) ha de estar estrechamente vinculado con el conocimiento de los intereses sociales que impulsan la creación y aplicación de los ordenamientos jurídicos con un concreto sentido u orientación? Pues el Proyecto del que hablo y que, por supuesto, es de mi exclusiva responsabilidad atribuírselo a Marra -para lo cual me apoyo en haber seguido su producción científica en los últimos diez años-, consiste en intentar desentrañar los fundamentos ideológicos de la más actual cultural jurídica dominante en Europa. Advierto que una afirmación de este tipo es absolutamente aventurada, tanto por la posibilidad de disentir con los propios deseos e intenciones de Marra cuanto por el riesgo que supone atribuir un objetivo que pueda considerarse desmesuradamente vasto. No obstante este peligro, insisto e adjudicar semejante objetivo al Proyecto que, según mi opinión, subyace en la obra de Marra y que, como lo entiendo, está muy agudamente orientado a poner al descubierto la sustancia funcionalista de esa cultura jurídica, lo que se comprueba con la selección de autores y obras hechas por Marra en su labor de investigación. Para ello mencionaré las «etapas» en que veo se va dividiendo su trabajo, con el cual ya ha alcanzado logros muy 
concretos y significativos. Antes de nada quiero decir que el Proyecto en cuestión supuso algo que me parece fundamental, cuando se trata de buscar las raíces de un sistema, de un modelo o de una ideología jurídica pues, es tan habitual encontrar teorías o firmes propuestas de principios que sólo se apoyan en el análisis puntual de los fenómenos observados que, cuando uno se encuentra con una manifiesta tentativa de descubrir los orígenes de un tipo de pensamiento jurídico como el que fundó el funcionalismo, no puede menos que aplaudir la investigación sobre los fundadores de semejante sistema de pensamiento. Aludo a la coherencia que revela de Marra entre el «hallazgo» de ciertos temas que son ejes centrales en la obra de aquellos autores-fundadores del funcionalismo jurídico y la construcción de ciertas teorías contemporáneas en el campo de la dogmática del derecho. Este aspecto califica por sí sólo y positivamente el mencionado Proyecto de Marra.

1. En una primera etapa Marra hizo una profunda revisión de la obra de Emile Durkheim. Esa revisión ha quedado plasmada en dos volúmenes; el primero de ellos -Il diritto in Durkeim (Sensibilità e riflessione nella produzione normativa), ESI, Napoli, 1986- recoge elaboraciones parciales sobre la obra durkeiminiana (algunas de ellas habían sido publicadas antes aisladamente) que, en su conjunto, analiza la gran reflexión de Durkheim sobre el derecho, siguiendo las distinciones que este autor propuso en $D e$ la division du travail social o sea, entre derecho represivo y derecho restitutivo y entre este último derecho basado sobre la solidaridad negativa o sobre la solidaridad positiva. Este esquema conceptual que ha servido a la divulgación de los fundamentos funcionalistas del derecho sirvió a Marra para puntualizar una interesante crítica a tal clasificación lo cual, a su vez, le permitió extenderse hacia otros aspectos. Pero, lo más sobresaliente del trabajo de Marra radica en haber destacado las grandes contribuciones de Durkheim en tema de pena (derecho penal), de propiedad (derecho de propiedad) y de contrato (derecho civil) las cuales, en definitiva, han contribuido a la consolidación de la sociedad occidental del S. XX sobre el modelo de la economía capitalista de concentración y sobre el cual ahora se pretende construir la «nueva» sociedad en el Este europeo, aunque la primera no constituya ningún modelo definitivamente positivo.

El segundo de los volúmenes de Marra que deseo mencionar es el que lleva por título Suicidio, diritto e anomia (Immagini delle morte volontaria nella civiltà occidentale), Quaderni «Dei 
Delitti a delle Pene» 2, ESI, Napoli 1987. En él se formula un lúcido ensayo sobre los elementos religiosos y morales que han influido en la conceptualización de la muerte voluntaria a través de los siglos y desde la civilización griega. Pero, la obra se concentra en la discusión de las tesis de Durkheim en torno a que la represión de la muerte voluntaria no puede considerarse una fase acabada en la historia del derecho penal. Con esta discusión que pone en juego la validez de tales tesis, Marra extrae la conclusión de que Durkheim habría evitado circunstanciadamente de extraer todas las consecuencias involucradas en la asunción general de la directa relación entre defensa de la dignidad de la persona y la intensidad de la represión del suicidio. Este punto sirve para un cuestionamiento global sobre el fundamento de validez de las obligaciones morales y jurídicas que, según Durkheim, sólo puede constituirse sobre fuertes valores morales. Desde esta perspectiva, a través de la reconstrucción histórica de las relaciones entre derecho represivo y calificación del suicidio en las cuales han influido tanto elementos religiosos como rituales, Marra pone en cuestión la posibilidad de explicar la fundación y los caracteres de un derecho penal moderno que parece mucho más influido, en razón de la dignidad de la persona humana, por la naturaleza de la idea de moral moderna.

2. La segunda etapa en el Proyecto de Marra que me estoy permitiendo distinguir, consiste en la labor de recuperación y reconstrucción de la obra de Max Weber, con fines específicas. Ya se conoce la producción de estudios sobre este autor y, sobre todo, lo que en tiempos últimos han procurado resaltar su contribución en la construcción de las denominadas democracias de masas. En Italia y particularmente en Génova se han hecho esfuerzos notables en este sentido; recientemente, G. Rebuffa -por citar a un conspicuo representante de la tradición que G. Tarello iniciara en la capital de Liguria- ha difundido dos trabajos muy vinculados a ese aspecto de la obra de Weber-Max Weber e la scienza del diritto, Torino 1989 y Nel crepuscolo della democrazia (Max Weber tra sociologia del diritto e sociologia dell Stato), Bologna 1991- con los cuales se confirma la orientación de aquellos esfuerzos, aunque otros estudiosos italianos y ligures han profundizado el pensamiento de Weber. Sin embargo me parece que la tentativa de Marra es de una amplitud diferente y, por tanto, la veo adscripta al mismo objetivo del Proyecto que me ha permitido atribuir a su labor científica. Es evidente que Weber, junto con su alumno Talcott Parsons han seguido la huella trazada por Emil Durkheim, por lo que los tres son considerados, pilares del funcionamiento jurídico. 
De este modo, que Marra haya dedicado la segunda etapa de su trabajo de investigación a la obra weberiana no es únicamente una coincidencia con el interés general despertado por ella en Italia y, particularmente en Génova, sino que supone un paso más en su tentativa de poner al descubierto los orígenes de una ideología jurídica concreta. No de otra manera deben interpretarse los dos importantes estudios que Marra ha dedicado al pensamiento de Weber, uno que particularmente atiende a un aspecto de fundamental importancia para descubrir sus raíces como es: Gli studi giuridici nella formazione di Max Weber (Heidelberg 1881, Berlino 1892) en «Materiali per una storia della cultura giuridica-Durkheim, XIX-2, ...y, otro, que atiende a las fuentes que Weber analizó para escribir su primer libro en el que se analizan las condiciones económicas que consintieron el nacimiento del capitalismo racional de empresa, cual es: Alle origini del capitalismo moderno. Max Weber e la <Geschichte der Handelsgesellschaften im Mittelalter $>$, también en «Materiali per una storia della cultura giuridica, XXI-1, 159-211. Ambos ensayos, como que se encuadran en una investigación financiada por el CNR de Italia, deben considerarse sólidamente vinculados entre sí.

Tal como lo vengo señalando y aún desconociendo si Marra continuará su investigación sobre Max Weber, supongo que su futuro trabajo atenderá a la obra de los seguidores de los «padresDurkheim del funcionalismo jurídico y puesto que en esa línea pueden considerarse diferentes autores, es posible que la labor se oriente hacia Talbott Parsons, Hans Bredemeier, William C. Evan, Laewrence M. Friedman o Niklas Luhmann; De esta forma, aunque esa suposición se extienda a un área de sociólogos, más que de juristas, su Proyecto adquiriría ya unas proporciones que desbordarían la reconstrucción histórica para introducirse en las expresiones contemporáneos del funcionalismo estructural y en las propias manifestaciones que la teoría de los sistemas está teniendo en el pensamiento jurídico.

II) La razón de carácter científico-epistemológico que, a su vez, me ha impulsado a escribir estas líneas se relaciona con el punto 3 de la Nota firmada por Realino Marra en Materiali per una storia della cultura giuridica, XXI-1, giugno 1991. Con el subtítulo Weber e la riconferma del dualismo tra dogmatica giuridica e sociologia del diritto, Marra desarrolla una sólida argumentación mediante la cual se cuestionan las orientaciones de fondo que expresaría una buena parte de las contribuciones recogidas en volumen El derecho y sus realidades, por mi 
coordinado. Aún más, esas orientaciones aparecerían ya señaladas en la misma Presentación: Por una sociología jurídica en España, que yo hiciera al libro. En consecuencia, me siento obligado a intentar una respuesta al cuestionamiento formulado por Marra aunque, desde ya, presiento que será difícil articularla en cuanto la argumentación formulada por él no sólo es sólida, sino también es correcta y veraz. No obstante, procuraré dar unas explicaciones con las que quizá se disipen las dudas expresadas por Marra acerca de la contradicción de fondo entre el objetivo declarado que él advierte en el volumen -obtener el reconocimiento de la sociología del derecho como parte integrante de la ciencia jurídica- y un supuesto acuerdo manifestado por mí y otros colaboradores, con las directivas metodológicas de Weber respecto de las soluciones «dualistas» en la fundamentación de la sociología del derecho.

Es oportuno adelantar que la contradicción apuntada por Marra parte de un punto de vista que da por definitiva la adopción por el subscripto (y por otros colaboradores en el volumen) de la así llamada "solución separatista", en el sentido que tradicionalmente se le ha adjudicado a este tipo de enfoque sobre las relaciones entre dogmática jurídica y sociología del derecho. Es verdad que semejante observación se apoya en alguna expresión por mí manifestada en la Presentación del volumen (v. p. III y ss.) cuando al pretender reseñar en una síntesis la constante tensión que se ha experimentado en los estudios jurídicos, entre las dos grandes soluciones propuestas en el terreno que se ha experimentado en los estudios jurídicos, entre las dos grandes soluciones propuestas en el terreno de las relaciones entre saber jurídico y saber sociológico -recogiendo en parte lo que Alberto Febbrajo (1978) ya había expuesto con suma claridad hace años-, señalé a Max Weber «como el más válido creador de la metodología adecuada a una sociedad jurídica idónea para comprender el papel que el derecho y los ordenamientos jurídicos deben cumplir en la sociedad contemporánea, dentro de la racionalidad burocrática». Sin embargo, más adelante, creo haber hecho algunas otras reflexiones respecto a la contraposición entre el propio enfoque de Weber, como diferenciador entre la dogmática jurídica y la sociología del derecho aunque aglutinando los puntos de vista del jurista cuanto los del sociólogo a partir de la identificación del poder, de la costumbre y de la economía que él hizo en su teoría sobre el derecho, y la de aquellos otros quienes, siguiendo a Kelsen, sólo se concentran en el análisis concreto de las normas positivas, de sus estructuras internas, de los elementos que configuran éstas, de las relaciones 
que vinculan a tales normas con otras (lo que se denomina el «sistema»), de lo que entienden por un ordenamiento jurídico vigente, etc.

Por otra parte, conviene también agregar que la posición de Weber, en cuanto opta por una "solución separatista" entre dogmática jurídica y sociología del derecho, no se corresponde homogéneamente con el tipo de «dualismo» que sostienen quienes son partidarios de la propuesta kelseniana. En este sentido, permítame Marra que recuerde aquí la tesis que su querido colega del Istituto di Filosofia e Sociologia del Diritto de Génova y su "casi" maestro Giorgio Rebuffa ha sostenido (v. 1989) respecto a la tentativa weberiana para resolver la constante tensión entre las dos grandes soluciones propuestas, tesis de la cual yo mismo me he valido en esa Presentación del volumen reseñado por Marra. Según Rebuffa, un análisis sociológico de los ordenamientos jurídicos modernos, debe entenderse como un estudio de los sistemas jurídicos no sólo en sus mecanismos de funcionamiento interno (normativo e institucional), sino también respecto a la función que éstos absuelven para el mantenimiento del orden social. De tal modo, es efectivamente cierto que la sociología jurídica se ocupa de comprender y explicar cómo y por qué los sistemas jurídicos satisfacen otras funciones más allá de la declarada de «regular los comportamientos». Descubrir las funciones, latentes y manifiestas, que satisfacen los sistemas jurídicos complejos es una tarea que obliga a combinar el conocimiento de los intereses sociales que impulsan la creación y la aplicación del derecho según determinadas orientaciones con el estudio de los elementos y las categorías que componen las normas. Por lo tanto, es presumible poder poner al descubierto ciertas funciones latentes -que reflejan con mucha fuerza la ideología que subyace a un determinado sistema- si se le atribuye a la sociología del derecho, junto a la tarea de analizar los comportamientos determinados por las normas jurídicas, también la de estudiar la incidencia que aquel tipo de intereses sociales tienen sobre estos elementos y categorías que configuran las normas. Realizando este tipo de trabajo científico se produce una convergencia de la sociología del derecho sobre el objeto de conocimiento de la dogmática jurídica: las normas y, posiblemente también, se podría corregir la separación radical entre deber ser y ser que, como bien dice Marra, es el aspecto que en la metodología weberiana provoca que ciencia jurídica y sociología del derecho se ocupen de objetos absolutamente diferentes entre sí.

Es entonces en el sentido indicado por último que corresponde 
discutir si es correcto insistir o no con la metodología weberiana para sostener la pertinencia de la sociología jurídica como disciplina jurídica, punto éste que sirve a Marra para señalar la contradicción de fondo entre el objetivo que él ha percibido como declarado por el volumen $E l$ derecho y sus realidades y dicha metodología.

No se equivoca Marra cuando al señalar esa contradicción de fondo destaca que con ella se toca muy de cerca un nudo todavía no resuelto de la fundamentación metodológica de la sociología del derecho. Este nudo estaría configurado por las diferencias de objeto de conocimiento que separa a la dogmática jurídica de la sociología del derecho, siempre que ésta no se ocupara de las «normas» sino sólo de los comportamientos que aquéllas determinan. Pero, dicho nudo se resolvería si el derecho es considerado como fenómeno social complejo dentro del cual el elemento normativo, aunque esencial, no puede escindirse de los factores externos que lo producen o que constituyen el marco o el objetivo de su actuación. De ese modo la unidad del objeto de conocimiento se reconstruiría en la perspectiva que Marra propicia de una ciencia social de los fenómenos normativos, ciencia que no podría ocuparse de una realidad de dos caras que, por tanto, debería ser estudiada bien por una ciencia «normativa», bien por otra social sin que el diverso punto de observación valga por sí para duplicar la entidad tomada bajo examen, provocando lo que Weber o también, más recientemente Hart, distinguían: normas o comportamientos, validez o eficacia. Las conclusiones a las que llega Marra son absolutamente legítimas para el estado de la cuestión, acerca de la configuración de la ciencia del derecho actual.

Por todo esto es que pienso que el cuestionamiento que ha formulado Marra en su recensión de El derecho y sus realidades es totalmente aceptable. Pero, lo que está por verse aún es, si en el estado del debate sobre la configuración de la ciencia del derecho actual es posible plantear una ciencia social de los fenómenos normativos, tal como Marra la propone, y si aquélla, por la vía de combinar el conocimiento de intereses sociales que impulsan la creación y aplicación del derecho con el estudio de los elementos y categorías normativos no salvaría la diferencia de objetos que separan a la dogmática de la sociología jurídica.

Otro aspecto del cuestionamiento de Marra que, sin embargo, él no ha relevado es el de saber si la contradicción que él ha señalado entre objetivo del volumen reseñado y metodología weberiana de la sociología jurídica es un tema que afecte o no a la institucionalización de la disciplina, sobre todo en España donde se sigue ignorando la necesidad de su enseñanza tanto a 
estudiantes de derecho como la de ciencias sociales. Este aspecto pienso que puede haber quedado mucho más claro en mi recordada Presentación: Por una sociología jurídica para España al volumen El derecho y sus realidades. De todos modos, remitiéndome a cuanto dije en esa sede quiero insistir aquí para decir que la situación no parece haber cambiado mucho desde entonces. En estos momentos, en trance de dar forma ya definitiva a los Planes de Estudio para las licenciaturas de Derecho, por una parte, y de Ciencias Sociales (Sociología), por la otra, en muy contados casos ha aparecido la propuesta de incluir la Sociología jurídica, como materia específica. De cualquier manera, allí donde se ha hecho la propuesta de incluir esta disciplina en tales Planes, siempre lo es con carácter de «optativa» y dependiendo de una materia troncal o principal, En todo caso, esas propuestas aparecen únicamente en los Planes de Estudio de Derecho y dependiendo de Filosofía del Derecho (como en el caso de la Universidad de Barcelona); no conozco que existiera un tipo de propuesta semejante en los Planes de Estudio de Sociología. En consecuencia, lo que debe presumirse es que, tal como Marra lo advirtiera, también en España se profundizaría la contradicción de fondo que él ha objetado en el terreno mismo de la enseñanza de la disciplina entre estatuto científico de la sociología jurídica y propuesta metodológica weberiana, con presumibles consecuencias de un continuado rechazo de los científicos del derecho para considerar la materia como parte de su ciencia jurídica, lo que perpetuaría su condición de subalternidad.

Este aspecto es preocupante. Convendría reflexionar más y en conjunto sobre él, pues pienso que una situación semejante se manifiesta en la universidad italiana, como en la alemana y seguramente en otras europeas. Entiendo que en las universidades latinoamericanas, donde la sociología jurídica no ha pasado por este proceso de vasallaje y se enseña desde largo tiempo, junto a otras disciplinas que no hacen parte de la ciencia del derecho en el sentido que discute Marra -tales como la antropología jurídica, la psicología jurídica, etc.-, aunque quizá mucho más vinculada al análisis del derecho como fenómeno «político», antes que jurídico.

Finalmente, la Nota de Realino Marra (Lo statuto scientifico della sociologia del diritto e la tutela weberiana) creo que ha sido muy importante, por lo menos para mí. Me ha hecho reflexionar y me ha ayudado a profundizar en el tema de la institucionalización académica de la disciplina. Pero, lo que tiene más trascendencia y seguramente beneficiará a otros lectores de dicha Nota es que, 
con ella, Marra se anota entre los estudiosos que más reflexivamente se han preocupado por la categoría epistemológica y metodológica de la sociología jurídica. 